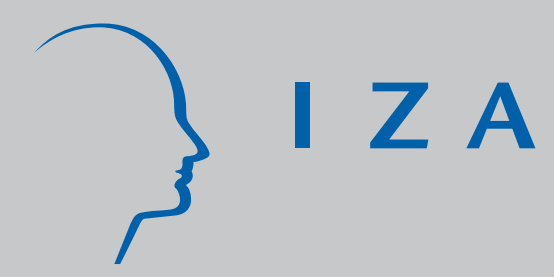

IZA DP No. 2269

Dispersion or Concentration for the 1.5 Generation?: Destination Choices of the Children of Immigrants in the US

Jamie Goodwin-White

August 2006 


\title{
Dispersion or Concentration for the 1.5 Generation? Destination Choices of the Children of Immigrants in the US
}

\author{
Jamie Goodwin-White \\ University of Southampton \\ and IZA Bonn
}

Discussion Paper No. 2269

August 2006

\author{
IZA \\ P.O. Box 7240 \\ 53072 Bonn \\ Germany \\ Phone: +49-228-3894-0 \\ Fax: +49-228-3894-180 \\ Email: iza@iza.org
}

Any opinions expressed here are those of the author(s) and not those of the institute. Research disseminated by IZA may include views on policy, but the institute itself takes no institutional policy positions.

The Institute for the Study of Labor (IZA) in Bonn is a local and virtual international research center and a place of communication between science, politics and business. IZA is an independent nonprofit company supported by Deutsche Post World Net. The center is associated with the University of Bonn and offers a stimulating research environment through its research networks, research support, and visitors and doctoral programs. IZA engages in (i) original and internationally competitive research in all fields of labor economics, (ii) development of policy concepts, and (iii) dissemination of research results and concepts to the interested public.

IZA Discussion Papers often represent preliminary work and are circulated to encourage discussion. Citation of such a paper should account for its provisional character. A revised version may be available directly from the author. 


\section{ABSTRACT \\ Dispersion or Concentration for the $\mathbf{1 . 5}$ Generation? Destination Choices of the Children of Immigrants in the US}

This paper examines determinants of inter-metropolitan destination choice for foreign-born and 1.5 generation adult children of immigrants in the US. An immigrant concentrationweighted accessibility parameter is included to assess the spatial structure of destination choice. A comparative origin-destination immigrant-native wage gap measure is also a strong determinant of destination choice, indicating the significance of relative labor market position. Although spatial assimilation perspectives would suggest that intergenerational social mobility should be connected with spatial dispersion, these models reveal the continuing importance of immigrant concentration for the 1.5 generation. When the destination concentration variable is added to reduced-form models, the positive effect of employment growth declines significantly, indicating that ethnic concentration may continue to be more important for the children of immigrants than more simply-framed economic conditions. Further, the increased model strength and parameter estimates associated with immigrant concentration and the accessibility measure suggest the spatial structure of destination choice depends on immigrant concentration at multiple scales - both to metro areas and to immigrant states or regions. The paper thus presents evidence for and suggests more attention to theorizing the geographic contexts of intergenerational immigrant incorporation.

JEL Classification: J61

Keywords: $\quad 1.5$ generation, internal migration, immigrant economic incorporation, spatial assimilation

Corresponding author:

Jamie Goodwin-White

Division of Social Statistics

Southampton Statistical Sciences Research Institute

University of Southampton

Southampton SW2 4QB

United Kingdom

E-mail: J.Goodwin-White@soton.ac.uk 


\section{Introduction}

Attention to the internal migration of immigrants in the US has increased dramatically over the last two decades. Concern with how immigrants will fare, both economically and socially, has been central to these inquiries. In part, these concerns are derived from spatial assimilation theories, in which immigrant dispersion from concentrations of co-ethnics is seen as a marker of immigrant incorporation on a social as well as a spatial level. Spatial assimilation ideas have traditionally been articulated within a local context, positing that immigrants move from concentrated urban cores to suburban locations as a result of their acculturation into the US (Alba et al 1999, Massey 1986). Geographers and other social scientists have recently suggested that questions of immigrant spatial incorporation should be extended to include other scales, including metropolitan, inter-metropolitan, and inter-state geographies. This jump involves the realization that internal migration is connected with processes that vary across scales, such as employment and housing opportunities, racial and ethnic social hierarchies and the politics of immigration itself (Wright and Ellis 2000, Wright, Ellis, and Parks 2004, Newbold 2004). The recent focus on the children of immigrants derives from an understanding that incorporation is very much an intergenerational process, and usefully studied as such.

Put simply, there is significant investment in the idea that immigrants will disperse from concentrated immigrant cities through internal migration, and that dispersal is part and parcel of the way in which immigrant incorporation takes place (Bartel 1989, Kritz and Nogle 1994). Although the evidence on this theory is mixed, it is not too early to consider the internal migration patterns of the rapidly growing second generation population. Where are the adult children of immigrants moving in the US? What are the determinants of where they choose to live? Do they follow their parents in their migration behavior? Are immigrant cities less important for the children of 
immigrants than for the first generation, as much of the immigration literature would seem to suggest? Answering these questions is an important step in disentangling the intergenerational processes of immigrant spatial incorporation.

This paper follows the analysis of an earlier one (Ellis and Goodwin-White, forthcoming) in which dichotomous logit models were used to assess the determinants and likelihood of inter-state migration for the 1.5 generation children of immigrants ${ }^{1}$, in comparison with immigrant and US-born (of US parentage) populations. State-level immigrant concentration at origin was found to be strongly and negatively associated with (out)migration, especially for the college-educated 1.5 generation. Not only was the 1.5 generation found to be even less likely to leave immigrant states than their foreignborn parents' generation, but the deterrent effect of concentration on mobility was even stronger for the most educated 1.5 generation individuals. Strikingly, two logical spatial assimilation assumptions, that 1) the second generation should be less constrained by the necessity of residence in an immigrant state than immigrants who arrived in the US as adults, and 2) that education should also increase the dispersion predicted by spatial assimilation, were overturned in this analysis. Instead, we concluded, the 1.5 generation may be likely to continue to reside in immigrant states precisely because they provide greater employment opportunities just as they do for US-born individuals. However, as we noted at the time, these logit models provided only half of the story on immigrant and 1.5 generation internal migration, since they focused solely on departure. It became clear from the inclusion of the origin concentration variable, which ended up driving the

\footnotetext{
${ }^{1}$ Although it is not possible to identify parental birthplace, and hence the proper $2^{\text {nd }}$ generation designation from the U.S. Census, the 1.5 generation (defined as those individuals who entered the U.S. prior to attaining twelve years of age) affords a suitable proxy. These individuals have doubtless had significant portions of their education in the U.S., and should therefore be less constrained in terms of residence and employment than their immigrant parents who immigrated to the U.S. as adults (Portes and Jensen 1987). They should also have had significant cultural experience in the U.S. by the time they reach 25 years of age (the minimum age considered in this analysis). Although the 1.5 generation as defined here are still immigrants, they will not be referred to as such throughout this paper. The terms foreign-born and immigrant refer specifically to those persons who arrived in the U.S. subsequent to their $12^{\text {th }}$ birthday, in order to avoid confusion.
} 
internal migration of immigrants and their children (and especially the college-educated) that inter-state dispersal in and of itself had little to do with intergenerational immigrant progress. Rather, the long-term geographies of immigrant settlement have emerged in ways that make location important for movers and stayers, and in which opportunities are differently available in different places - largely as a result of the historical immigrant geography of the US both locally and regionally.

The models discussed in this paper thus attempt to compare destination choice of the 1.5 generation with the foreign-born who arrive as adults, and the role of immigrant concentration in destination choice. Since I am also concerned with the variation in immigrant-native wage gaps in and between local labor markets, these models focus on metro-level destination choice. They include well-known determinants of internal migration customarily used in these types of models, such as distance, labor force size, housing value, and employment. An immigrant concentration measure at destination and an immigrant concentration weighted accessibility measure are included, as well as a migration-specific inequality measure. While it would make sense from a spatial assimilation perspective that 1.5 generation destination choice would be more sensitive to economic concerns such as labor force size and employment growth, and less sensitive to the geography of ethnic settlement, I do not expect this to be the case as a result of the earlier findings on inter-state migration propensities discussed above. The addition of these new immigrant-specific variables into destination choice models are thus an attempt to acknowledge the spatially-segmented nature of immigrant and 1.5 generation destination choice, in that they take into account the relative positions of immigrants and their children in ethnic wage and social structures. While spatial assimilation ideas associate decreasing concentration with immigrant progress, the spatially-segmented tack taken here expects that continuing metro-level concentration may not be incommensurate with economic success. Factors such as relative labor 
market position may be associated with the continuing importance of metro-level concentrations in destination choice, especially for the adult children of immigrants.

\section{Theoretical Background}

The idea that immigrant residential integration with the US-born population is a measure of their assimilation has been a continuing focus of immigration research (Massey 1986; Massey and Denton 1993; Alba, Logan, and Crowder 1997; Alba, Logan et al 1999). Spatial assimilation theory derives from classical Chicago School ideas about immigrant progress from the ghetto to the suburbs, and has continually been formalized in the immigration literature as an intra-urban process. Specifically, spatial assimilation suggests that as immigrants make socioeconomic progress and adapt culturally into the US mainstream, they will move from highly-concentrated central city locations to less ethnically-isolated suburbs. As a result of this move, they acculturate yet further and provide opportunities for structural assimilation for their children, mainly through proximity to the US-born. Lieberson's (1980) definition of assimilation as the "point at which it is no longer possible to predict occupational status by someone's ethnicity" could thus be extended to spatial assimilation as no longer being able to predict one's residence by their ethnicity. Obviously, this is far from being the case in the US either occupationally or spatially, but the use of Lieberson's logic here points out the importance of host society discrimination as the other side of assimilation's two-way street. Surprisingly, though, this is often forgotten. Most often, it is only undertheorized, in that the context of reception - of discrimination that might impact residential choice- is neglected. In the emphasis on dispersal and mobility, the implications of specific origins and destinations are often not compared. 
This is especially the case when spatial assimilation ideas are extended to scales beyond the urban area, as is common in both popular and academic discourse on immigrant concentration. Bartel (1989), for example argues that the positive relationship between education and choice of less ethnically-concentrated metro areas by immigrant internal migrants in the 1980 s is evidence for spatial assimilation. Kritz and Nogle (1996) note that the presence of co-ethnics deters out-migration from Canadian cities for the most-educated migrants. Both of these analyses are notable in that they concentrate on co-ethnic rather than immigrant concentration, confusing the assimilation issue in the process. Bartel's analysis, specifically, would define immigrant assimilation as residence apart from US-born co-ethnics. This literature, taking the classical emphasis on dispersion as assimilation, considers the critical element of place for immigrants to be the presence or absence of co-ethnics, rather than the contextual processes that might underlie such residential patterns.

Segmented assimilation's critical caution that immigrant adaptation is dependent upon race and context of settlement (rather than simple dispersion) is derived from spatial assimilation ideas. For segmented assimilation perspectives focus on the two possible outcomes of assimilation: one into mainstream (US-born, but often white) spaces and another into non-mainstream (immigrant, non-white) spaces. In part, these explanations remain more sociological than spatial, as they consider behavioral outcomes of residential location, rather than attempting to theorise geographic context. They have been central to discussions of how the children of immigrants will fare because of fears of dissonant acculturation, in which immigrant children acculturate to an "oppositional" and damning ethnic underclass as a result of their concentrated and segregated locations. ${ }^{2}$ Although much of this fear has proceeded from a cultural basis, concern

\footnotetext{
${ }^{2}$ Although what Hirschman (2001) terms the "immigrant optimism hypothesis" spins segmented assimilation more positively, emphasizing that the children of Asian immigrants have prospered as a
} 
with the gross inequalities and bleak employment prospects of the immigrant cities where much of the second generation live has begun to direct much scholarship on intergenerational prospects (see, for example, Clark 2001 and Zhou 2001). However, despite ideas that second generational occupational and educational progress depends on their location in the US, with a related focus on the imperative of their dispersal from immigrant concentrations, ${ }^{3}$ there has been little attention to their internal migration. There has also been little empirical attention to the specific social and labor market contexts of the cities in which they live. ${ }^{4}$ The contributors to Waldinger's Strangers at the Gates (2001), comparing immigrant progress in five immigrant cities provide a prototype, with Zhou's chapter a preliminary inquiry into second generation educational and occupational attainment.

For the most part, the second generation literature to this point has concerned itself with whether the children of immigrants will close their parents' gap with the USborn of US parents. While segmented assimilation's prognoses of a second generation underclass (Gans 1992, Massey 1995, Portes and Zhou 1995) have been prominent, they have also been supplanted by cautious assessments of substantial second generation social mobility, largely through education (Hirschman 2001, Zhou 2001, Farley and Alba 2002, Fry 2002). Some scholars have suggested that the current second generation are progressing just as the earlier second generation of European immigrants did (Waldinger 1996, DiNardo, Card, and Estes 2000).

At any rate, while there are strong rationales associated with assumptions of 1.5 generation dispersal and the connection of this dispersal to socioeconomic progress,

result of their location in concentrated communities that encourage educational rigor. See also Kao and Tienda (1995).

${ }^{3}$ Although Zhou (2001) finds that the second generation in Los Angeles, while economically disadvantaged in the labor market, has access to educational resources and at least minimal employment opportunities.

${ }^{4}$ There has, however, been significant attention to how different national contexts affect second generation incorporation (eg Boyd 2002, Van Tubergen et al). For a review see Reitz (2002). 
such ideas are worth investigating. It is doubtful that immigrant ethnic geographies have played such a small role that dispersal is associated so unproblematically with socioeconomic progress. The investigation of destination choice is a first step toward answering these questions, in that determinants of mobility can be connected with locational choice. Origin-specific models for those immigrants who leave New York and Los Angeles refine this analysis by providing information on the destination choices of the foreign-born and 1.5 generation leaving these two immigrant cities. This allows investigation of the expanded-scale spatial assimilation suggestions that immigrants and their children would do better to leave these highly unequal immigrant cities, and that doing so is an indicator of acculturation to the US The addition of immigrant concentration variables and a pan-metro immigrant concentration accessibility measure open up these questions to consideration of the interaction of scales and the social structure of spatial choice. An additional migration-specific inequality variable explicitly considers immigrant/native differentials across locations as related to internal migration.

Accessibility: theory and application to immigrant destination choice

In that these models attempt an understanding of the spatial structure of internal migration, they include an accessibility variable relating the probability of destination choice $j$ to all other destinations. In effect, the accessibility parameter is a populationweighted distance function relating all possible destinations, such that:

$$
A_{j}=\sum_{k \neq j} W_{k} / d_{j k}
$$


where $A_{j}$ is the accessibility of potential destination $\mathrm{j}$ to all other potential destinations $\mathrm{k}$, $d_{j k}$ is the distance between destinations ${ }^{5}$, and $W_{k}$ is a population weight (Fotheringham 1991). Although it is common for accessibility measures to weight by overall population size similar to a gravity model formulation, the $W_{k}$ employed in these models is instead the percentage of metro area population that is foreign-born. As such, the interpretation of $A_{j}$ for these models is of the accessibility of metros that have foreign-born concentrations.

The initial development of competing destinations approaches stemmed from the realization of a misspecification of the distance decay parameter in destination choice modeling. Destination choice models define place utility as the sum of all characteristics that attract migrants from origin, such as labor force size, housing prices, and distance. Theoretically, all potential destinations with equivalent utility in this sense should be equally likely choices of a migrant from origin i. This, however, is to assume that choice of destination is unrelated to the spatial structure relating destinations to each other. Instead, it was theorized, individuals process migration choices hierarchically, such that a first-stage subset of possible destinations (a regional cluster, for example) is considered initially, and the specific sub-destination considered next. In that migrants are hypothesized to search for a specific set of amenities at a certain distance cost, they are likely to underestimate (relative to place utility) competing clustered destinations relative to more isolated destinations. Migrants are less likely, ceteris paribus, to select a destination with high accessibility to other destinations of comparable utility. As such, the accessibility parameter is seen as a critical correction to migration models in which

\footnotetext{
${ }^{5} d_{j k}$ are measured in great circle distances from metro area centroids.
} 
population and distance based utility locations are considered without reference to each other (Pellegrini and Fotheringham 1999).

The accessibility measure employed in this paper, however, weights destinations' distance from each other by foreign-born share of total destination population. As such, this is a measure of the accessibility of metro-level immigrant concentrations to each other. While there is the expectation that the parameter estimate of accessibility $(\alpha)$ is negative in line with the spatial competition thesis discussed above, $\alpha>1$ would be consistent with the existence of agglomeration forces among potential destinations, such that destinations in larger clusters are more likely to be chosen. ${ }^{6}$ This presents interesting opportunities for considering the significance of foreign-born concentration across scales, as will become apparent in discussion of model results.

\section{Destination choice models of internal migration}

This paper thus reports the initial results of a series of destination choice models for immigrants and the 1.5 generation. Models are further restricted to household heads 25 years of age or older, with active labor force status (in full-time paid employment and not self-employed). All models are based on a matrix of flows between 240 metropolitan statistical areas taken from the 2000 Public Use Microdata Files. ${ }^{7}$ The cells include counts of movers for each of 57,360 (240 X 239) inter-metro area flows, although only just over half $(25,418)$ of these flows are populated by heads of household with active labor force status. Poisson models are conducted separately for immigrant and 1.5 generation heads of household, in order to avoid the problem of non-independently determined moves.

\footnotetext{
${ }^{6}$ Obviously, if $\alpha=1$ the accessibility specification is unnecessary as the assumption of destination choice modeling that all destinations with equivalent utility are equally likely to be chosen is correct.

${ }^{7}$ All data come from the PUMS, with the exception of the Housing Affordability measure, taken from a 2000 report of the National Association of Home Builders.
} 
As in most destination choice models, distance and population variables form the reduced models, and provide a basis for comparison and assessing the relevance of additional covariates. Population is measured at destination, and is here specified as the adult population in the labor force. Just as in gravity-based models, distance is expected to reduce the attraction of destinations, and labor force size is expected to exert a positive pull. Both the population and distance variables are logged, as this has been shown to considerably reduce model deviance and improve fit (Flowerdew and Lovett 1988). Additional covariates include destination economic indicators such as 1995-2000 employment growth and median housing value, foreign-born concentration measures, and an origin-destination immigrant/native wage gap. All are discussed more thoroughly in what follows. All models are developed through several specifications allowing examination of the importance of adding new covariates and addressing theoretical perspectives on foreign-born/1.5 generation destination choice. In these and the sets of models that follow, Model 1 is the reduced form spatial interaction model including only destination labor force size (LNLF00) as a measure of destination attraction and a logged distance from origin to destination (LNDIS). Model 2 then adds economic variables including the inequality measure, model 3 the foreign-born concentration variable, and model 4 the concentration accessibility measure.

Model 2 thus includes several economic characteristics of origins connected with destination choice. New employment (NEWEMP) is a measure of all new jobs created in the five-year period from 1995-2000. ${ }^{8}$ Median housing value (MHSVAL) is included as a measure of pricing and cost parity between destinations. In addition to these customary economic indicators, a migration specific foreign-born/native wage gap (ijRELWAGE) was calculated. This variable is expected to be positively associated with

\footnotetext{
${ }^{8}$ Unemployment at destination was not included as a result of the high degree of endogeneity often found when using this measure (as new migrants to an area are likely to be unemployed).
} 
destination choice for the foreign-born and the 1.5 generation. ijRELWAGE is set equal to the 2000-1995 relative wage gap at the mean between immigrants and the US-born for each flow, such that:

ijRELWAGE = 2000avg(immigrant/native) -1995avg(immigrant/native)

This relative income difference is assessed for all 25-54 year-old men and women heads of household who work full-time all-year (and are not self-employed or in group quarters) in the labor force. It is expected that individuals will choose destinations where they are better off (relatively, when compared with the US- born) relative to where they came from. ${ }^{9}$

Model 3 then includes two foreign-born concentration variables. The first (FBj) is an absolute measure of foreign-born concentration at destination. The second (FBij) compares the percentage of the population that is foreign-born at origin and destination (FBij) as follows:

$\% \mathrm{FB}_{\mathrm{ij}}=\% \mathrm{FB}_{\mathrm{j}}-{ }^{-} \% \mathrm{FB}_{\mathrm{i}}$

The two different concentration variables allow for differentiation of the attractions of concentrated immigrant destinations absolutely, as well as relative to origin. Again, as discussed above, theoretical expectations would hold that immigrant concentrations are less important for the 1.5 generation than their parents, and that economic considerations should increase in relative importance. However, I do expect that

\footnotetext{
${ }^{9}$ It was originally added separately and subsequently to NEWEMP and MHSVAL in order to assess the impact of immigrant/native inequality independently of more conventional economic variables. Although ijRELWAGE is significant and improved model fit when added after other economic covariates, it had very little impact on any other model variables, and so was not worth the space of presenting separate models. This means that ijRELWAGE is not only a significant predictor of destination choice, but also that it acts independently of other (non-comparative) economic variables, having little collinearity.
} 
foreign-born concentration will be a positive determinant of metro-level destination choice for the 1.5 generation, just as it was in constraining inter-state migration.

Finally, Model 4 includes the accessibility covariate (FBACC) as discussed in the preceding section. The significance of this variable will indicate the extent and the direction to which spatial structure within the US (but beyond the sale of a US metro area) impacts destination choice. Following an unconstrained origin specification, Models 1-4 are repeated in origin-specific models for those leaving Los Angeles and New York.

Largest Migration Streams

Before proceeding to model results, however, it is useful to have some understanding of the inter-metropolitan flows of the foreign-born and 1.5 generation between 1995 and 2000, especially in line with suggestions of intergenerational dispersion. The largest flows for foreign-born and 1.5 generation groups are reported overall, and disaggregated for those with a high school education or less and those who have at least some college education.

$<<$ Table 1 about here $>>$

While the top twenty flows listed here in each case constitute a sizable share of the 25,418 possible flows (between 15 and 20\% in each case), the top flows constitute an even greater share of total migration for the 1.5 generation than for the foreign-born, even when controlling for education. Although these top flows are dominated by outmigration from Los Angeles and New York, 2 of the top 6 flows for the 1.5 generation 
are return flows to Los Angeles from San Diego and San Francisco. It is important to note the significance of other West Coast destinations for the least-educated (whether foreign-born or 1.5 generation). The Los Angeles-Las Vegas flow dominates intermetropolitan migration for the high school educated, and is important for the overall foreign stock population (but not for the college-educated). A Los Angeles-Phoenix flow is similarly if less strongly important, and even Denver becomes a top destination for the less-educated foreign-born. These lower-cost lower-skilled metros are doubtless more important as destinations from Los Angeles in 2000 than in 1990. The top LAVegas flow also captures a much greater proportion of the 1.5 generation than it does the foreign-born.

Although these flows are represented among the top few for less-educated migrants, the top flows for college-educated migrants remain in the top 5 most concentrated foreign-born cities. Table 1 provides some evidence that 1.5 generation migrants are even more likely than the foreign-born to continue to be driven by top internal flows - some of which involve moves to Los Angeles and continuing concentration there. Education is not likely to attenuate this pattern, as it is actually the least-educated foreign-stock who are attracted to newer immigrant destinations. This substantiates earlier findings that the 1.5 generation (especially the college-educated) were less likely than their immigrant parents' generation to leave concentrated immigrant states (Ellis and Goodwin-White, forthcoming). Internal migration may be a mechanism of seeking out less vulnerable positions in local labor and housing markets, rather than a measure of economic or social achievement. The models that follow therefore focus on both immigrant concentration and relative wages in destination choice. 


\section{Model Results}

Unconstrained Origin Models of Destination Choice

$<<$ Table 2 about here $>>$

Wage inequality and immigrant concentrations drive both foreign-born and 1.5 generation choice, as shown in Table 2. The initial reduced Model 1 shows expected results, although it is perhaps surprising at first glance that the 1.5 generation seem more constrained by distance than their foreign-born parents' generation. Adding destination economic variables in Model 2 improves model fit considerably, as indicated by the strong decrease in the deviance statistic. New employment is strongly positive for both groups (although more so for immigrants, perhaps more dependent on new jobs for employment), and median housing value is slightly positive (more so for the 1.5 generation), as is the migration-specific inequality covariate..$^{10}$

Quite interestingly, this migration-specific immigrant-native relative wage measure outperformed simpler inequality measures as a predictor of destination choice. A simple average wage measure for immigrants for 1995-2000 movers at destination, a destination-origin (2000-1995) average for immigrants and a destination-only immigrant/wage gap all failed to be significant when an origin-destination flow specific immigrant/native gap was included. (As such, this is the only inequality variable remaining in the models.) The fact that absolute (non-relative) immigrant income (2000-1995) and destination-only immigrant/native income differentials are insignificant when the chosen variable is included is a sign that immigrants and 1.5ers do not only

\footnotetext{
${ }^{10}$ Interestingly, a previous iteration (not reported here) where a simple immigrant/native wage ratio(FBNBAVG) at destination was reported showed that the estimate of this variable was slightly negatively associated with destination choice, whereas ijRELWAGE is positive. This indicates that destination choice is not necessarily positively associated with a move to increase wages relative to the U.S.-born, but to do so relative to where one currently lives.
} 
make destination choices that benefit them absolutely through destination choice, or choose places in which they experience less income inequality vis-à-vis the US-born. Instead, destination choice has much to do with one's relative (to US-born individuals) position in a labor market - relative to one's wage position at origin. This suggests that much could be gained from thinking about relative wages across local labor markets as part of the geographic context within which we assess immigrant incorporation.

The most interesting findings, however, occur with the introduction of the foreign-born concentration covariates in Model 3, which yields by far the greatest proportional model improvement. Foreign-born concentration at destination is a strongly significant attractor of internal migration, both absolutely and relative to origin foreign-born concentration. The significance of FBij and FBj indicate that foreign-born and 1.5 generation migrants are more likely to go to places where the foreign-born concentration is higher compared with other destinations, and higher compared with place of origin. Rather than abating generationally, however, it is arguably as strongly associated with destination choice for the 1.5 generation than for the foreign-born who arrived as adults, when both measures are examined.

The concentration variables are strongly collinear with other covariates and diminish their significance, with the exception of the relative wage covariate (ijRELWAGE) which remains relatively robust through all model iterations. The positive effects of absolute labor force size and median housing value are strongly diminished. More importantly, the extreme attraction of metro areas with high levels of employment growth in 1995-2000 is strongly diminished with the addition of the foreign-born concentration variables. For the foreign-born, employment growth diminishes as an attractor by more than $2 / 3$, while it is rendered insignificant for the 1.5 generation. While foreign-born concentration has often been seen to deter outmigration (see for example Bartel and Koch 1991, Kritz and Nogle 1994), it is a 
hallmark of spatial assimilation conceptions that concentration should diminish as an attractor over time (and by extension, intergenerationally). In these models of destination choice, estimated for those who are already migrants, destination concentration is a significant determinant of where to move. Further, the 1.5 generation is no less attracted by foreign-born concentration than the foreign-born population. The resulting decline in employment growth (now insignificant for the 1.5 generation) means that much of the attractor effect of destinations with high employment growth may in fact be explained by the presence of foreign-born concentration in these metros. Although it would be expected that foreign-born concentrations should decline in significance for the 1.5 generation, especially relative to employment conditions, this is demonstrably not the case here.

The final full model introduces the accessibility function, which demonstrates the importance of regional-level immigrant settlement in destination choice. It is similarly strong and positive for both the foreign-born and the 1.5 generation, and improves model fit substantially. Further, the distance decay parameter is decreased slightly by the introduction of the accessibility measure, and more so for the 1.5 generation -suggesting that they may be more likely to migrate at greater distances to be nearer agglomerations of foreign-born concentrations (like those in the Western US). ${ }^{11}$ Larger clusters thus evidence a significant multiplier effect. For the 1.5 generation, the addition of the accessibility measure substantially increases the magnitude of the relative concentration variable FBij, while diminishing the absolute concentration measure FBj. This indicates that the spatial clustering of concentrated destinations relative to origin was subsuming some of the importance of the relative concentration measure in model 3. Although it is challenging to interpret this finding theoretically, this is at least some

\footnotetext{
${ }^{11}$ And also clarifying why the distance decay variable in Model 1 had a stronger effect on the 1.5 generation than on the foreign-born.
} 
evidence of a socially-networked immigrant space that functions across scales, such that metro-level foreign-born destinations are chosen with regard to immigrant regions. Perhaps this explains the strong within-west coast focus of flows and counterflows of Table 1, especially evidenced for the college-educated. At any rate, this is evidence that there is a socio-spatial structure to foreign-born and 1.5 generation migration decisionmaking, one that has significant ramifications for potential spatial assimilation of the children of immigrants.

Moving from Immigrant Cities: Origin-Specific Models for Los Angeles and New York

Origin-specific destination choice models (Tables 3 and 4) were conducted for migrants leaving Los Angeles and New York in order to understand whether destination choice was different for migrants leaving these two largest foreign-born concentrations. This provides a useful focus, since previous findings that the foreign-born and the 1.5 generation are unlikely to leave concentrated foreign-born states (Kritz and Nogle 1994, Ellis and Goodwin-White) translate into questions of where those who do leave immigrant concentrations go.

$<<$ Tables 3, 4 about here $>>$

Destination choice for foreign-born and 1.5 generation individuals leaving Los Angeles differs notably from the overall models in several ways. Employment is a strongly positive determinant of destination choice for those leaving Los Angeles, one that is much stronger for the foreign-born than the 1.5 generation. Although employment at destination remains significant (if strongly diminished) as an attractor for the foreign- 
born throughout these models, it retains much more magnitude after controlling for concentration for those leaving Los Angeles specifically. (New employment at destination does not remain significant for the 1.5 generation leaving Los Angeles after accounting for foreign-born concentration). There is little doubt that the large numbers of recent immigrants in Los Angeles have regional internal migration patterns driven largely by the search for employment. The inequality variable ${ }^{12}$ is a positively significant determinant of destination choice for the 1.5 generation, even as it is not for the foreignborn. Foreign-born concentration at destination is a strong attractor of migration from Los Angeles, much more so for the 1.5 generation than for the foreign-born, and significantly diminishes the effects of other covariates when included. As in previous models, collinearity with employment growth in indicated, although new jobs remain a significant determinant of destination choice for immigrants.

These findings point to an interesting conclusion regarding foreign-born and 1.5 generation destination choice from Los Angeles. New employment matters not at all for 1.5ers once foreign-born concentration at destination (strongly positive) is taken into account, yet the inequality measure remains significant and shows no evidence of collinearity. This provides additional if slight support for the earlier suggestion that 1.5 generation opportunity may be greater in foreign-born concentrations, just as the initial employment opportunity may be for their immigrant parents' generation. In other words, the 1.5 migrants leaving Los Angeles are choosing foreign-born concentrations and places where their wages relative to the US-born are higher. However, ideas that employment growth drives in-migration are challenged by the fact that this variable is subsumed by the attraction of foreign-born concentrations.

\footnotetext{
${ }^{12}$ Which reduces to an immigrant/native average wage ratio (FBNBAVG)here, as origin is held constant.
} 
This is not as true for the foreign-born, however, for whom new employment remains a significant aspect of destination choice even after controlling for foreign-born concentration. Here, it is the foreign-born who respond more to a traditional economic concern in choosing migration destinations, although foreign-born concentration is still quite important. For the 1.5 generation, ethnic concentration is more important than employment growth. So, however, is income inequality with the US-born - a measure of why the unequal labor markets of US cities are critical to studies of destination choice. Again, this may provide evidence of a spatially-segmented assimilation - in which dispersion may be less important that comparative labor market opportunities. In other words, immigrant concentrations may be critical for first generation employment (as the immigrant enclave literature has established) - but also for the chance for subsequent generations to improve their stakes relative to everyone else. The accessibility variable is extremely strong and positive, indicating large agglomeration effects. Given an outmigration from Los Angeles, both the foreign-born and the 1.5 generation are very strongly inclined to choose a highly accessible foreign-born concentration (probably one in California or nearby). This parameter is more than twice as strong for the foreignborn as for 1.5ers, indicating perhaps a stronger regionalization of destination choice for the foreign-born. The significantly increased distance parameter for the 1.5 generation clarifies the regional accessibility issue further, as it increases sizably for less accessible concentrations.

All of these effects are part and parcel of Los Angeles' unique situation as a foreign-born concentration with a nearby network of additional foreign-born concentrations, in California and the Western US more generally. It is apparent that the historical settlement of the foreign-born in the US has played a part in the continuing concentration of this region, and that the phenomenon of movements between concentrations within this region is akin (on a larger scale) to the increasing 
suburbanization predicted intra-regionally by spatial assimilation theory. That is to say, dispersal has its own undoing - as more of the foreign-born move to satellite concentrations, and shape them in the process. The only surprising part about this is that the effect is stronger for the 1.5 generation than for the foreign-born themselves.

Destination choice for migrants from New York, however, is a somewhat different story - probably largely because of its distance from the border. Distance decay is far less significant from New York than from Los Angeles, and labor force size and new employment far more positive determinants of destination choice. (However, employment growth is rendered insignificant by the addition of destination foreign-born concentration, just as in previous models, and this is even more dramatically so for the 1.5 generation.) Again, foreign-born concentration at destination is strongly positive, and more so for the 1.5 generation than for the foreign-born. Mostly, New York differs in that the accessibility parameter is negatively associated with destination choice. This is very strongly the case for the 1.5 generation, for whom it becomes so strong in Model 4 as to render distance insignificant (although accessibility is insignificant for the foreignborn leaving New York). Rather than agglomeration forces, then, accessibility is associated with competition effects for 1.5 ers leaving New York. This is at least in part the result of a strong new York-Miami retirement flow, and also migration to Los Angeles. Not least, of course, this is probably due to Los Angeles' border location, New York's distance from it, and the importance of Mexico as the top sending country. But at any rate migrants leaving New York, while just as likely to make destination choices driven by choosing metro-level foreign-born concentrations as migrants from Los Angeles, are less likely to choose destinations located in regional concentrations - and those tend to be near both previous and future generations of migrants, in places that facilitate ongoing and cyclical patterns of immigration. 


\section{Discussion and Conclusions}

Expectations that the 1.5 and $2^{\text {nd }}$ generation children of immigrants will disperse away from concentrated sites of ethnic settlement are probably unwarranted. Evidence presented in an earlier paper demonstrates that foreign-born concentration at origin deterred inter-state migration even more for the 1.5 generation than for their parents, suggesting that spatial assimilation's connection of dispersal with immigrant incorporation is problematic. The finding that the negative effect of concentration on out-migration was even stronger for the college-educated foreign-born and 1.5ers suggested further that immigrant states may provide opportunities in terms of employment for the foreign-stock population in much the same way these large states do for the US-born population. Further, this relationship may in part be due to the historical nature of immigrant settlement, which has led to very different contexts of opportunity (especially for the foreign-stock population) in some places compared with others.

The extension of inter-state migration models to metro-level destination choice models in this paper provides additional evidence for a spatially-segmented conception of internal migration (rather than a purely spatial model), in that it is possible that immigrant and 1.5 generation progress will occur with regard to already highly-developed metro-level and regional concentrations. Uniformly, across all of these models, foreignborn concentration at destination shows no sign of declining in importance for the 1.5 generation, for whom it is often more important than it is for the foreign-born. Most astonishingly, these models show, it is likely that employment growth is subsumed by immigrant concentration with regard to destination choice (with the exception of the foreign-born leaving Los Angeles). The fact that high collinearity exists between these two place characteristics is not surprising, but the fact that the destination concentration 
variable continues to be as (more!) significant for the 1.5 generation as for their parent's foreign-born generation is.

Or perhaps not. Accessibility measures demonstrate considerable agglomeration effects of destination choice, such that not only is destination choice attributable to foreign-born concentration at destination - but that destinations clustered within a regional concentration are more likely to be chosen. There is, then, an interaction of scales and a regional as well as a metro-level structure to these immigrant geographies one that persists and arguably, strengthens rather than abates, by the 1.5 generation. At the same time, a variable measuring relative wage differentials with the US-born, relative again to origin and destination, is strongly significant even after adding the concentration variable to the models. This is to say that internal migration for foreign-stock individuals is positively determined not so much by how one stands to gain from a move, as how one stands to gain relatively. In part, as these model iterations demonstrate, it may not be so much that immigrants choose foreign-born concentrations as that they don't choose places with very low levels of foreign-born concentration. There are, probably, few advantages gained from a move to these places for all migrants, whether US- or foreign-born. However, it is doubtless that the history of immigrant settlement has much to do with the configuring of socio-spatial patterns that make the opportunity of possible structures vary widely for the foreign-born and the 1.5 generation.

In summary, destination choice is strongly driven by foreign-born concentration at destination, and even more so for the 1.5 generation - despite what assimilation theorists would say about expected intergenerational dispersion. In part, this seeming inconsistency stems from the extension of spatial assimilation ideas from an intra-urban to an inter-urban scale. It is far more complicated to theorize how intergenerational progress is associated with leaving New York or Los Angeles than it is to suggest that a 
move to suburban residence within a city connotes structural assimilation. ${ }^{13}$ And yet, such ideas are continuously prevalent. Concentration may "cancel out" employment growth as an attractor largely because the types of employment growth may not reflect jobs the foreign-born and their children get - as the strongly positive significance of a migration-specific relative foreign-born/native wage measure indicates. This indicates the need for better understanding of foreign-born and 1.5 generation selectivity in destination choice, in order to untangle the determinants and consequences of internal migration on immigrant and 1.5 generation wage outcomes.

The exceptions to the overall story (otherwise exceedingly consistent), of course, occur for those migrants leaving New York or Los Angeles. First, employment growth remains significant alongside foreign-born concentration as factors in destination choice for the foreign-born leaving Los Angeles. This may be a result of the fact the Los Angeles holds more than its share of relatively recent labor migrants, such that these migrants are moving with regard to work above all else. Second, the accessibility measure of destination choice for those leaving New York indicates competition rather than agglomeration forces in regional destination choice. Again, this is probably due to the fact that major "foreign-born concentrations" are farther and fewer between than on the West Coast. What both of these exceptions point out is that more substantial understandings of immigrant geography and comparative understandings of how immigrants fare in local labor markets are necessary to make any sense of the relation of internal migration and dispersion to immigrant progress.

More significant than these two exceptions are the consistently strong findings that foreign-born concentration in cities still matters - more than employment growth and more for the 1.5 generation. And the significance of the foreign-born

\footnotetext{
${ }^{13}$ Although this intra-urban conception is far from unproblematic, as has been argued (Alba et al 1999, Rosenbaum and Freedman 2001).
} 
concentration-weighted accessibility measure suggests that concentration matters at regional scales as well - such that much of the southwestern US has a seeming cast of a networked cluster of concentrated cities. These findings, along with the similarly consistent finding that immigrants (and especially the 1.5 generation) choose places where they are relatively better off with reference to the US-born and relative to whence they came, is evidence that spatial assimilation ideas are in even greater need of critique when it comes to the children of immigrants. This makes a good deal of sense. The dispersion model, after all, comes from an idea that immigrants initially settle in concentrated neighborhoods, cities, and states due to their unfamiliarity with US culture. Yet this unfamiliarity is not a characteristic of 1.5 generation adults who came of age in the US It is easy to imagine that continuing foreign-born concentration at the scale of a city or region might be advantageous for the children of immigrants, especially in terms of sustaining opportunities for the college-educated.

There is certainly some early evidence for this in addition to this paper and the study on inter-state migration that preceded it. Several researchers find that immigrant cities and states provide opportunities for the foreign-born to avoid the worst sorts of jobs, or at a minimum offer relatively higher employment prospects (Zhou 2001, Waldinger and Feliciano 2004). As Waldinger and Feliciano suggest, "The penetration of immigrant networks is also now very deep, which, in southern California or Texas, means that there are still plenty of Mexican sweepers and sewing machine operators, but also quite a few foremen and skilled workers, which in turn provides the second generation with access to job opportunities well above the bottom" (2004: 385). And as Light (2002) and Pamuk (2004) point out, the Los Angeles and San Francisco growth machines resulted from the machinations of Asian ethnic concentration and resources, as well as those of US-born whites, with positive effects for the second and subsequent generations. Along with Meyerson's (2004) analysis of how Latino immigrant and 
second generation neighborhood concentration yields political and economic power in Los Angeles in recent years, these accounts provide additional evidence of why the use of spatial assimilation falters at any scale when it comes to the children of immigrants.

But most precisely, it falters because it fails to take into account that the children of immigrants are not immigrants so much as "ethnics". Immigrant cities should have different meanings and consequences for the 1.5 generation, largely as a result of the history of immigrant settlement, as Lieberson and Waters remind us, which has ramifications for political power-sharing and access to employment in a region. The problem with focusing on dispersion and concentration, as measures, is that we obscure the comparative contexts of cities as places. For a highly-educated second generation Latino, Los Angeles may not be an ideal place to be - until you look at the lessconcentrated alternatives with fewer appropriate employment opportunities. 1.5 generation immigrants are even more likely to choose a concentrated destination than their parents' generation, and the effect carries across scales from cities to states to regions. And concentration continues to exert positive effects beyond those of straight employment conditions. Immigrant cities, in the end are multicultural cities, which makes then much more than just unassimilated concentrations of non-whites.

\section{Acknowledgements}

This research was funded in part by the NIHCD under grant number 5 T32 HD07543. I am very grateful for the helpful suggestions of Mark Ellis and Suzanne Withers, as well as the institutional support provided by the Center for Studies in Demography and Ecology (CSDE) at the University of Washington. 
References

Alba R, Logan J, Stults B, Marzan G, Zhang W. 1999. Immigrant groups in the suburbs: A reexamination of suburbanization and spatial assimilation. American Sociological Review 64: 446-60.

Alba R, Logan J, Crowder K. 1997. White ethnic neighborhoods and spatial assimilation: The Greater New York region, 1980-1990. Social Forces 75: 883-912.

Bartel A. 1989. Where Do the New US Immigrants Live? Journal of Labor Economics 74: $371-391$.

Bartel AP, Koch MM. 1991. Internal Migration of New US Immigrants. In Immigrants, Trade, and the Labor Market, Abowd JM, Freeman R (eds.); University of Chicago Press: Chicago; 121-34.

Boyd M. 2002. Educational Attainments of Immigrant Offspring: Success or Segmented Assimilation? International Migration Review 36: 1037-60.

Clark WAV. 2001. The Geography of Immigrant Poverty: Selective Evidence of an Immigrant Underclass. In Strangers at the Gates: New Immigrants in Urban America, Waldinger R (ed.); University of California Press: Berkeley, Los Angeles; 159-85.

DiNardo J, Card D, Estes E. 2000. The More Things Change: Immigrants and the Children of Immigrants in the 1940s, the 1970s, and the 1990s, In Issues in the 
Economics of Immigration, Borjas G (ed.); National Bureau of Economic Research for University of Chicago Press: Chicago.

Ellis M, Goodwin-White, J. 2006 (in press). Dispersing from States of Immigration?: 1.5 Generation Internal Migration in the US. International Migration Review 40(4).

Farley R, Alba R. 2002. The new second generation in the United States. International Migration Review 36: 669-701.

Flowerdew R, Lovett, A. 1988. Fitting Constrained Poisson Regression Models to Interurban Migration Flows. Geographical Analysis 20(4): 297-307.

Fotheringham AS. 1991. Migration and spatial structure: the development of the competing destinations model. In Migration Models: Macro and Micro Approaches, Stillwell J, Congdon P (eds.); Belhaven: London; 57-72.

Fry R. (2002). Work or Study: Different Fortunes of US Latino Generations. Pew Hispanic Center: Washington, DC.

Gans HH. 1992. Second-Generation Decline: Scenarios for the Economic and Ethnic Futures of the Post-1965 American Immigrants. Ethnic and Racial Studies 15: 173-192.

Hirschman C. 2001. The Educational Enrollment of Immigrant Youth: A Test of the Segmented-Assimilation Hypothesis. Demography 38: 317-336. 
Kao G, Tienda M. 1995. Optimism and Achievement: The Educational Performance of Immigrant Youth. Social Science Quarterly 76: 1-19.

Kritz MM, Nogle. JM 1994. Nativity Concentration and Internal Migration among the Foreign-Born. Demography 31(3): 509-24.

Lieberson S, Waters M. 1987. The Location of Ethnic and Racial Groups in the United States. Sociological Forum 24: 780-810.

Lieberson S. 1980. A Piece of the Pie: Blacks and White Immigrants Since 1880. University of California Press: Berkeley.

Light I. 2002. Immigrant Place Entrepreneurs in Los Angeles, 1970-99. International Journal of Urban and Regional Research 26(2): 215-28.

Massey D. 1986. The Settlement Process Among Mexican Migrants to the United States American Sociological Review 51: 670-85.

Massey D. 1995. The New Immigration and Ethnicity in the United States. Population and Development Review 21 (3): 631-652.

Massey D, Denton N. 1993. American Apartheid. Harvard University Press: Cambridge.

Meyerson H. 2004 A Tale of Two Cities. The American Prospect. May 17. 
Newbold KB. 2004. Segmented Paths and the Differential Role of Primate Immigrant Centers. Geographical Analysis 36(1): 21-37.

Pamuk A. 2004. Geography of Immigrant Clusters in Global Cities: A Case Study of San Francisco, 2000. International Journal of Urban and Regional Research 28(2): 287-307.

Pellegrini PA, Fotheringham AS. 1999. Intermetropolitan migration and hierarchical destination choice: a disaggregate analysis from the US Public Use Microdata Samples. Environment and Planning A 31: 1093-1118.

Portes A, Jensen L. 1987. What's an Ethnic Enclave? The Case for Conceptual Clarity, American Sociological Review 52: 768-70.

Portes A, Zhou M. 1995. Divergent Destinies: Immigration, Poverty and Entrepreneurship in the United States. In Poverty, Inequality and the Future of Social Policy: Western States in the New World Order, McFate K, Lawson R, Wilson WJ (eds.); Russell Sage Foundation: New York; 489-520.

Reitz JG. 2002. Host Societies and the Reception of Immigrants: Research Themes, Emerging Theories and Methodological Issues. International Migration Review 36 (4): 1005-1019.

Rosenbaum R, Friedman S. 2001. Immigration, Assimilation, and Inequality Differences in the Locational Attainment of Immigrant and US-Born Households with Children in New York City. Demography 38(3): 337-348. 
Van Tubergen F, Maas I, Flap H. 2004. The Economic Incorporation of Immigrants in 18 Western Societies. American Sociological Review 69(5): 704-19.

Waldinger R. 2001. Strangers at the Gates: New Immigrants in Urban America. University of California Press: Berkeley.

Waldinger R, Feliciano C. 2004. Will the new second generation experience 'downward assimilation'? Segmented assimilation re-assessed. Ethnic and Racial Studies 27(3): 376402.

Wilson K, Portes A. 1980. Immigrant Enclaves: An Analysis of the Labor Market Experiences of Cubans in Miami. American Journal of Sociology 88: 295-319.

Wright R, Ellis M. 2000. Race, Region and the Territorial Politics of Immigration in the US International Journal of Population Geography 6: 197-211.

Wright R, Ellis M, Parks V. 2005. Re-Placing Whiteness in Spatial Assimilation Research. City and Community 4: 111-36.

Zhou M. 2001. Progress, Decline, Stagnation? The New Second Generation Comes of Age. In Strangers at the Gates: New Immigrants in Urban America. Waldinger R (ed.); University of California Press: Berkeley. 
Zhou M, Logan J. 1989. Returns on Human Capital in Ethnic Enclaves: New York City's Chinatown. American Sociological Review 54: 809-20 
Table 1- Top Foreign-Stock Migration Flows, 1995-2000, by education

\begin{tabular}{|c|c|c|c|c|c|c|c|c|c|}
\hline \multirow[t]{22}{*}{ Foreign-Born } & & movers & $\%$ & & HS movers & $\%$ & & college movers & $\%$ \\
\hline & 1 NY-MI & 9841 & 1.71 & LA-LV & 6500 & 2.89 & NY-MI & 5300 & 1.51 \\
\hline & 2 LA-LV & 8863 & 1.54 & NY-MI & 4541 & 2.02 & LA-SF & 4976 & 1.42 \\
\hline & 3 LA-SF & 8222 & 1.43 & LA-PHX & 4251 & 1.89 & NY-DC & 4132 & 1.18 \\
\hline & 4 NY-DC & 5645 & 0.98 & LA-SF & 3246 & 1.45 & SF-LA & 3243 & 0.93 \\
\hline & 5 LA-PHX & 5531 & 0.96 & LA-DEN & 2780 & 1.24 & NY-SF & 3212 & 0.92 \\
\hline & 6 NY-PHL & 4975 & 0.87 & LA-CHI & 2238 & 1.00 & NY-LA & 3100 & 0.88 \\
\hline & 7 SF-LA & 4740 & 0.82 & LA-DAL & 2123 & 0.95 & NY-PHL & 3055 & 0.87 \\
\hline & 8 LA-SD & 4688 & 0.82 & LA-SD & 1963 & 0.87 & LA-SD & 2725 & 0.78 \\
\hline & 9 NY-LA & 4606 & 0.80 & NY-PHL & 1920 & 0.86 & NY-ATL & 2646 & 0.75 \\
\hline & 10 NY-ATL & 4427 & 0.77 & NY-ORL & 1920 & 0.86 & DC-NY & 2497 & 0.71 \\
\hline & 11 LA-NY & 4064 & 0.71 & LA-ATL & 1805 & 0.80 & LA-NY & 2485 & 0.71 \\
\hline & 12 NY-ORL & 3890 & 0.68 & NY-ATL & 1781 & 0.79 & LA-LV & 2363 & 0.67 \\
\hline & 13 LA-DEN & 3680 & 0.64 & LA-PTL & 1618 & 0.72 & NY-BOS & 2072 & 0.59 \\
\hline & 14 NY-BOS & 3627 & 0.63 & LA_NY & 1579 & 0.70 & BOS-NY & 2014 & 0.57 \\
\hline & 15 NY-SF & 3456 & 0.60 & NY-BOS & 1555 & 0.69 & NY-ORL & 1970 & 0.56 \\
\hline & 16 LA-DAL & 3185 & 0.55 & NY-DC & 1513 & 0.67 & SD-LA & 1782 & 0.51 \\
\hline & 17 SD-LA & 3160 & 0.55 & NY-LA & 1506 & 0.67 & CHI-NY & 1773 & 0.51 \\
\hline & 18 LA-CHI & 3063 & 0.53 & SF-LA & 1497 & 0.67 & NY-CHI & 1759 & 0.50 \\
\hline & 19 LA-SEA & 2887 & 0.50 & HOU-DAL & 1435 & 0.64 & PHL-NY & 1743 & 0.50 \\
\hline & 20 SF-SAC & 2796 & 0.49 & LA-DC & 1403 & 0.62 & SF-SAC & 1618 & 0.46 \\
\hline & \multicolumn{4}{|c|}{9534616.58} & 47174 & 21.01 & & 54465 & 15.54 \\
\hline \multicolumn{10}{|l|}{ 1.5 Generation } \\
\hline & 1 LA-SF & 2953 & 1.93 & LA-LV & 1177 & 3.27 & LA-SF & & 2.23 \\
\hline & 2 NY-MI & 2460 & 1.61 & NY-MI & 664 & 1.84 & NY-MI & 1796 & 1.54 \\
\hline & 3 LA-SD & 2151 & 1.41 & LA_SD & 601 & 1.67 & LA-SD & 1550 & 1.33 \\
\hline & 4 LA-LV & 1801 & 1.18 & LA-PHX & 560 & 1.55 & SF-LA & 1171 & 1.00 \\
\hline & 5 SD-LA & 1496 & 0.98 & NY-ORL & 393 & 1.09 & NY-DC & 1124 & 0.96 \\
\hline & 6 SF-LA & 1367 & 0.90 & SD-LA & 373 & 1.03 & SD-LA & 1123 & 0.96 \\
\hline & 7 NY-DC & 1256 & 0.82 & LA-SEA & 355 & 0.98 & NY-LA & 1115 & 0.96 \\
\hline & 8 NY-BOS & 1212 & 0.79 & LA-SF & 349 & 0.97 & NY-BOS & 1055 & 0.90 \\
\hline & 9 NY-LA & 1195 & 0.78 & NY-ATL & 322 & 0.89 & NY-PHL & 956 & 0.82 \\
\hline & 10 NY-PHL & 1177 & 0.77 & SF-STK & 294 & 0.82 & BOS-NY & 947 & 0.81 \\
\hline & 11 SF-SAC & 1109 & 0.73 & LA-ATL & 249 & 0.69 & NY-SF & 941 & 0.81 \\
\hline & 12 NY-ATL & 1046 & 0.69 & LA-PTL & 246 & 0.68 & SF-SAC & 905 & 0.78 \\
\hline & $13 \mathbf{L A}-\mathbf{N Y}$ & 995 & 0.65 & LA-CHI & 233 & 0.65 & PHL-NY & 895 & 0.77 \\
\hline & 14 BOS-NY & 968 & 0.63 & NY-PHL & 221 & 0.61 & LA-NY & 894 & 0.77 \\
\hline & 15 NY-SF & 941 & 0.62 & LA_HOU & 213 & 0.59 & NY-ATL & 724 & 0.62 \\
\hline & 16 PHL-NY & 895 & 0.59 & LA_DEN & 207 & 0.57 & DC-NY & 643 & 0.55 \\
\hline & 17 LA-SEA & 884 & 0.58 & NY-NOR & 206 & 0.57 & LA-LV & 624 & 0.54 \\
\hline & 18 LA-PHX & 858 & 0.56 & SF-SAC & 204 & 0.57 & SF-SD & 613 & 0.53 \\
\hline & 19 NY-ORL & 791 & 0.52 & LA-DAL & 201 & 0.56 & SF-NY & 598 & 0.51 \\
\hline & 20 DC-NY & 702 & 0.46 & SF-LA & 196 & 0.54 & SAC-SF & 578 & 0.50 \\
\hline \multicolumn{5}{|c|}{2625717.20} & 7264 & 20.15 & & 20856 & 17.89 \\
\hline
\end{tabular}


Table 2 - Unconstrained Destination Choice Models

\begin{tabular}{|c|c|c|c|c|}
\hline unconstrained models & Model 1 & Model 2 & Model 3 & Model 4 \\
\hline FB movers & reduced & +economic & $+\% \mathrm{imm}$ & + access \\
\hline Intercept & -8.1539 & -7.3213 & -4.3155 & -9.0279 \\
\hline LNDIS & $-0.6236 * * *$ & $-0.6896 * * *$ & $-0.7302^{* * *}$ & $-0.7107 * * *$ \\
\hline LNLF00 & $1.0782 * * *$ & $0.9652^{* * *}$ & $0.7153^{* * *}$ & $0.9260^{* * *}$ \\
\hline NEWEMP & & $1.0048^{* * *}$ & $0.2992^{* * *}$ & $0.1601^{*}$ \\
\hline MHSVAL & & $0.0826^{* * *}$ & $0.0782^{* * *}$ & 0.0020 \\
\hline ijRELWAGE & & $0.0591 * * *$ & $0.0465^{* * *}$ & $0.0455^{* * *}$ \\
\hline$\% \mathrm{FBij}$ & & & $0.1466^{* * *}$ & $0.2406^{* * *}$ \\
\hline$\% \mathrm{FBj}$ & & & $0.0365^{* * *}$ & $0.0101^{* * *}$ \\
\hline FBACC & & & & $1.4633^{* * *}$ \\
\hline Scale & 9.2702 & 9.1568 & 8.9962 & 8.3101 \\
\hline deviance & 2184085 & 2130734 & 2056469 & 1754686 \\
\hline scaled deviance & 25415 & 25412 & 25410 & 25409 \\
\hline
\end{tabular}

\section{5 movers}

Intercept

$\begin{array}{llll}-8.9664 & -7.8436 & -3.3497 & -8.4731\end{array}$

LNDIS

$-0.9342^{* * *}$

$-0.9902 * * *-1.0240 * * *-0.9031 * * *$

LNLF00

$1.1333 * * *$

$0.8527 * * * \quad 0.5317 * * * \quad 0.7852^{* * *}$

NEWEMP

$0.9071 * * * \quad-0.0074 \quad 0.1073$

MHSVAL

$0.2172^{* * *} \quad 0.1516^{* * *} \quad 0.0434 * * *$

ijRELWAGE

$\% \mathrm{FBij}$

$\% \mathrm{FBj}$

FBACC

$0.0718^{* * *} \quad 0.0537 * * * \quad 0.0545 * * *$

$0.0654 * * * \quad 0.1739 * * *$

$0.0745^{* * *} \quad 0.0396 * * *$

$1.3767 * * *$

$\begin{array}{lllll}\text { Scale } & 3.9908 & 3.9614 & 3.8641 & 3.6628\end{array}$

deviance $413663 \quad 398786 \quad 379401 \quad 340891$

scaled deviance

25415

25412

$25410 \quad 25409$

${ }^{*} \mathrm{p}<.05 ;{ }^{* *} \mathrm{p}<.01 ; * * * \mathrm{p}<.001$

$*$ Standard errors adjusted for overdispersion. 
Table 3 - Origin (Los Angeles) Specific Models

\begin{tabular}{|c|c|c|c|c|}
\hline Los Angeles Origin & Model 1 & Model 2 & Model 3 & Model 4 \\
\hline FB movers & reduced & +economic & $+\% \mathrm{imm}$ & + access \\
\hline Intercept & \multicolumn{2}{|c|}{$-3.5866-3.3691$} & -2.2251 & -20.6391 \\
\hline LNDIS & \multirow{7}{*}{$\begin{array}{r}-0.9713^{* * *} \\
1.2308\end{array}$} & $-1.2541 * * *$ & $-1.1274 * * *$ & $-1.5423^{* * *}$ \\
\hline LNLF00 & & $1.3022^{* * *}$ & $1.2689 * * *$ & $1.2778^{* * * *}$ \\
\hline NEWEMP & & $0.7554 * * *$ & $0.4915^{* *}$ & $0.3226^{*}$ \\
\hline MHSVAL & & $-0.1717 * * *$ & $-0.1045^{* * *}$ & $-0.0835^{* * *}$ \\
\hline ijRELWAGE & & -0.0222 & -0.0046 & -0.0025 \\
\hline$\%$ FBij & & & $0.2555^{* * *}$ & $0.2630^{* * *}$ \\
\hline FBACC & & & & $8.4613^{* * *}$ \\
\hline Scale & 16.1237 & 14.7567 & \multicolumn{2}{|c|}{13.252812 .5183} \\
\hline deviance & 61353 & 50738 & 40747 & 36199 \\
\hline scaled deviance & 236 & 233 & 232 & 231 \\
\hline \multicolumn{5}{|l|}{1.5 movers } \\
\hline Intercept & -6.8213 & -6.9367 & -4.4120 & -14.5430 \\
\hline LNDIS & $-1.2817 * * *$ & $-1.2764 * * *$ & $-1.3077 * * *$ & $-1.5862 * * *$ \\
\hline LNLF00 & $1.4793^{* * *}$ & $1.5208^{* * *}$ & $1.3061 * * *$ & $1.3328^{* * *}$ \\
\hline NEWEMP & & $0.7954 * * *$ & -0.1427 & -0.2057 \\
\hline MHSVAL & & -0.0328 & -0.0381 & -0.0373 \\
\hline ijRELWAGE & & $0.0460 * * *$ & $0.0443 * *$ & $0.0505^{* * *}$ \\
\hline$\% \mathrm{FBij}$ & & & $0.3416^{* * *}$ & $0.3361 * * *$ \\
\hline FBACC & & & & 4.7471 \\
\hline Scale & 7.2854 & 7.0932 & 6.2491 & 6.1401 \\
\hline deviance & 12526 & 11723 & 9060 & 8708 \\
\hline scaled deviance & 236 & 233 & 232 & 231 \\
\hline
\end{tabular}


Table 4 - Origin (New York) Specific Models

\begin{tabular}{|c|c|c|c|c|}
\hline New York Origin & Model 1 & Model 2 & Model 3 & Model 4 \\
\hline FB movers & reduced & +economic & $+\% \mathrm{imm}$ & + access \\
\hline Intercept & -10.1876 & -10.0222 & -7.1067 & -5.9001 \\
\hline LNDIS & $-0.2953 * * *$ & $-0.3602^{* * *}$ & $-0.4805^{* * *}$ & k $-0.4673^{* * *}$ \\
\hline LNLF00 & $1.3534 * * *$ & $1.4600^{* * *}$ & $1.1985^{* * *}$ & k $1.1974 * * *$ \\
\hline NEWEMP & & $1.1820^{* * *}$ & -0.4339 & -0.4328 \\
\hline MHSVAL & & -0.0887 & -0.0315 & -0.0331 \\
\hline ijRELWAGE & & 0.0246 & 0.0148 & 0.0144 \\
\hline$\% \mathrm{FBij}$ & & & $0.3546^{* * *}$ & $0.3526^{* * *}$ \\
\hline FBACC & & & & -0.5671 \\
\hline Scale & 19.0617 & 18.1710 & 14.6408 & 14.6718 \\
\hline deviance & 83570 & 74952 & 48436 & 48433 \\
\hline scaled deviance & 230 & 227 & 226 & 225 \\
\hline \multicolumn{5}{|l|}{1.5 movers } \\
\hline Intercept & -13.9610 & -14.0316 & -10.2551 & 36.3302 \\
\hline LNDIS & $-0.4272^{* * *}$ & $-0.5165^{* * *}$ & $-0.6749 * * *$ & -0.1222 \\
\hline LNLF00 & $1.5551 * * *$ & $1.7904 * * *$ & $1.4396^{* * *}$ & $1.4363^{* * *}$ \\
\hline NEWEMP & & $1.5777 * * *$ & -1.3349 & -1.2531 \\
\hline MHSVAL & & $-0.1859 * * *$ & $-0.0975^{*}$ & $-0.1600 * * *$ \\
\hline ijRELWAGE & & $0.0480^{*}$ & 0.0308 & -0.0007 \\
\hline$\% \mathrm{FBij}$ & & & $0.4635^{* * *}$ & $0.3813^{* * *}$ \\
\hline FBACC & & & & $-2.2668^{* * *}$ \\
\hline Scale & 10.0309 & 9.3821 & 7.5365 & 7.3454 \\
\hline deviance & 23142 & 19981 & 12838 & 12139 \\
\hline scaled deviance & 230 & 227 & 226 & 225 \\
\hline
\end{tabular}

